\title{
Experimental Investigation of Cutting Forces in High-Feed Milling of Titanium Alloy
}

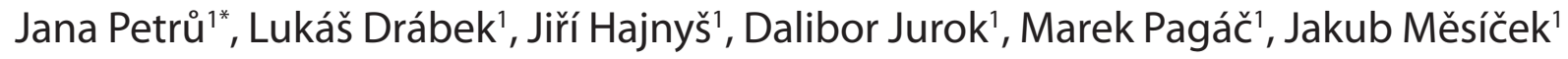 \\ 1 Faculty of Mechanical Engineering, VSB-Technical University of Ostrava, 17. listopadu 2172/15, Ostrava \\ Poruba 708 00, Czech Republic \\ * Corresponding author's e-mail: jana.petru@vsb.cz
}

\begin{abstract}
Titanium super alloys are often used in the chemical and aerospace industries, especially because of financial savings, resulting primarily from cheaper operation of equipment. Machinability of titanium alloys is more difficult than that of other metals. In addition, the low thermal conductivity causes the alloy to stick to the cutting edge of the cutting tool, thereby causing it to become dull faster. The article deals with the experimental evaluation of cutting forces and the design of suitable cutting parameters for the machining of the UNS R56260 titanium alloy with high-feed milling technology. Testing was carried out in climb and conventional milling under different cutting conditions. The cutting components of forces Fx, Fy, Fz were measured and evaluated. The results of the measurements were processed into a graphical form and suitable cutting conditions were designed in terms of the acting cutting forces.
\end{abstract}

Keywords: high-feed milling, titanium alloy, cutting forces

\section{INTRODUCTION}

The high-feed milling technology used provides high material removal with high tool feed. This type of machining is used in large-scale and mass production, where the advantages of this technology will be most apparent. It is important to choose a suitable tool and machine with appropriate cutting parameters. The current trend is to increase the efficiency and productivity using new machines, tools and technologies.

In their article, Li et al. [2017] dealt with chip morphology and the mechanism of their formation, cutting forces, cutting power and specific cutting technology. Another article dealing with the study of cutting forces in milling titanium alloys is from Sun et al. [2015]. The experiment concerned the effect of feed per tooth on the cutting force and cutting power with index-coated carbide inserts. The results showed that the cutting force increases along with feed per tooth, especially in the direction of the width of cut [14]. In their article, Liu et al. [2016] dealt with reducing the tool wear and improving the quality of material processing during machining. The experimental results showed that under certain parameters, liquid nitrogen can reduce the cutting force and cutting temperature while improving the tool life and the quality of the surface being machined [9]. In their article, Ji et al. [2015] investigated high-speed milling of titanium alloy using a polycrystalline diamond. They verified the capability of machining a polycrystalline diamond at high speed dry machining, taking into account the influence of tool geometry. Subsequently, they evaluated the tool wear in different planes [6].

Safari et al. [2015] investigated the effects of cutting conditions and tool wear on surface integrity in dry milling titanium alloy. Various cutting conditions were used during the experiment. The results showed that surface roughness values at different cutting speeds directly depend on the tool conditions [13]. Xu et al. [2013] carried out a series of experiments to investigate the 
cutting force during milling of a titanium alloy. Individual experiments were conducted with different speeds of milling feed. The results showed that the cutting force shows an increasing trend with an increase in feed per tooth [16]. Okada et al. [2014] addressed the impact of oil mist on the milling process. It was experimentally demonstrated that at a cutting speed of $25 \mathrm{~m} / \mathrm{min}$, the tool temperature dropped by about 50 to $100^{\circ} \mathrm{C}$, compared to dry milling. The effect of oil mist was particularly evident at lower cutting speeds [12]. Barnett-Ritcey and Elbastawi [2002] tested various tools under different cutting conditions using compressed air, dry milling, coolants, and monitored tool wear. Guilin [2017] dealt with machining of titanium alloy, and cutting parameters of machining were chosen on the basis of analysis of orthogonal wear tests. On the basis of wear results, suitable cutting parameters were chosen for milling titanium alloy [4]. In papers [1, 5, 2, $11,15]$, the authors described the used material titanium alloy, tool wear after milling and system of study tool wear.

The research was focused on face milling of titanium alloy. The experiment was carried out at the Technical University of Ostrava, Faculty of Mechanical Engineering, and was machined on the DMU 50 milling center. The aim was to evaluate the pre-selected cutting parameters in terms of THE cutting components of forces. The evaluation was carried out for all selected cutting parameters of both climb and conventional milling. The cutting forces were measured using a Kistler 9129AA dynamometer. The results of the measured cutting forces were given in the conclusion.

\section{EXPERIMENT CONDITIONS}

The experiment deals with high-feed milling of the UNS R56260 titanium alloy. The material was machined by face milling technology using a single cutting insert with evaluation of the action of cutting components of forces at different cutting speeds. The milling tools and indexable cutting inserts were purchased from Ingressol Cutting Tools.

In the experiment, the cutting conditions, i.e. "cutting speed" $v_{c}\left(\mathrm{~m} \cdot \mathrm{min}^{-1}\right)$ and "feed per tooth" were changed $f_{z}(\mathrm{~mm})$. Depth of cut $a_{p}(\mathrm{~mm})$ or width of cut $a_{e}(\mathrm{~mm})$ remained constant throughout the experiment. Before starting the experiment, it was necessary to clamp a dynamometer into the machining center, which, during the whole experiment, recorded the action of cutting forces induced from the tool to the workpiece. In order to fasten the UNS R56260 titanium alloy to the dynamometer, four holes were drilled to place the screws in the workpiece. Subsequently, the material was clamped to the dynamometer. Moreover, the workpiece had to be milled prior to the experiment for easier clamping and better handling of the titanium alloy. The Kistler 9129AA dynamometer was used in the experiment to record the cutting forces during the process, namely in the $F_{x}, F_{y}$ and $F_{z}$ axes. The measured values were transferred to numerical values and read using DynoWare. The obtained values were processed and subsequently evaluated into graphs and tables. The experiment was performed on a DMU 50 5-axis milling center from DMGMORI. DMGMORI produces quality $\mathrm{CNC}$, machining centers and state-of-the-art 5-axis machines. Inside, the machine has a built-in HeidenhainiTNC 530 HSCI control system with postprocessor.

\section{CUTTING TOOL AND INDEXABLE INSERT FOR UNS R56260 ALLOY}

A 5W7G052R00 six-cutter milling machine from Ingerssol Cutting Tools was chosen for machining. Only one indexable cutting insert was clamped into the tool. Indexable cutting inserts by Ingerssol Cutting Tools were used, trade name RHKW1003M0TN.

\section{SPECIFIED CUTTING CONDITIONS FOR THE EXPERIMENT}

The material was machined using one-edge face milling technology. The UNS R56260 titanium alloy was first machined by conventional
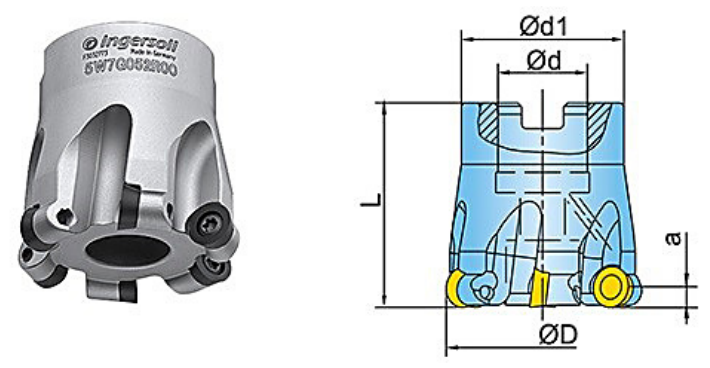

Fig. 1. 5W7G052R00 from Ingerssol Cutting Tools [7] 
Table 1. Basic dimensions of the milling machine 5W7G052R00 by Ingerssol Cutting [7]

\begin{tabular}{|c|c|c|c|c|c|}
\hline$\varnothing \mathrm{D}[\mathrm{mm}]$ & $\varnothing \mathrm{d}[\mathrm{mm}]$ & $\varnothing \mathrm{d} 1[\mathrm{~mm}]$ & $\mathrm{a}[\mathrm{mm}]$ & $\mathrm{L}[\mathrm{mm}]$ & Number of teeth \\
\hline 52 & 22 & 40 & 2 & 50 & 6 \\
\hline
\end{tabular}

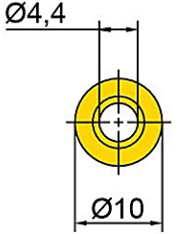

$\underline{3,8}$
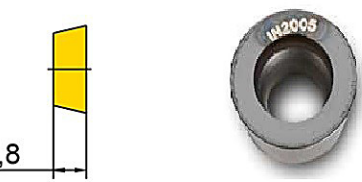

Fig. 2. VBD RHKW1003M0TN by Ingerssol Cutting Tools [10]

milling and then by climb milling, under the same conditions as given in Table 3.

\section{MEASUREMENT AND EVALUATION OF CUTTING FORCES}

The measurement of dynamic forces during high feed milling was performed by means of KISTLER 9129AA dynamometer. This dynamometer is used to determine the force conditions during milling. The KISTLER 9129AA dynamometer measures cutting forces in 3 directions: $F_{x}$ - normal cutting forces perpendicular to the component $F_{y}$;

$F_{y}$ - cutting forces acting in the direction of the feed of the tool;
$F_{z}$ - compressive or passive cutting forces acting in the direction of the tool axis.

Figure 3 shows that the smallest measured values of the cutting force components are, for constant feed per tooth milling $f_{z}=0.25 \mathrm{~mm}$, at a cutting speed $v_{c}=80 \mathrm{~m} \cdot \mathrm{min}^{-1}$ and feed speed $v_{f}=0.137 \mathrm{~m} \cdot \mathrm{min}^{-1}$. They also show that the value of the cutting component $F_{x}$ is almost negligible at all cutting speeds up to the smallest, which is at a cutting speed $v_{c}=50 \mathrm{~m} \cdot \mathrm{min}^{-1}$. Furthermore, Table 6 shows the increasing components of cutting forces $F_{y}$ and $F_{z}$ at increasing cutting speeds $v_{c}$.

Figure 4 indicates that the smallest measured values of the cutting forces are, for constant feed per tooth climb milling $f_{z}=0.4 \mathrm{~mm}$, at a cutting speed $v_{c}=130 \mathrm{~m} \cdot \mathrm{min}^{-1}$ and feed speed $v_{f}=0.357 \mathrm{~m} \cdot \mathrm{min}^{-1}$. The chart also shows that the cutting component $\mathrm{F}_{\mathrm{x}}$ is absolutely negligible due to small measured values.

Figure 5 illustrates that the smallest measured values of the cutting force components are, for constant feed per tooth climb milling $f_{z}=0.6 \mathrm{~mm}$, at a cutting speed $v_{c}=80 \mathrm{~m} \cdot \mathrm{min}^{-1}$ and feed rate $v_{f}=0.329 \mathrm{~m} \cdot \mathrm{min}^{-1}$. The chart also shows that the cutting component $F_{x}$ is absolutely negligible due to small measured values.

Table 2. Parameters of ICI RHKW1003M0TN by Ingerssol Cutting Tools [10]

\begin{tabular}{|c|c|c|c|}
\hline Thickness $[\mathrm{mm}]$ & $\varnothing \mathrm{D}[\mathrm{mm}]$ & $\varnothing \mathrm{D} 1[\mathrm{~mm}]$ & Recommended feed per tooth $\mathrm{f}_{z}[\mathrm{~mm}]$ \\
\hline 3.8 & 10 & 4.4 & $0.25-0.6$ \\
\hline
\end{tabular}

Table 3. Cutting parameters for titanium alloy UNS R56260

\begin{tabular}{|c|c|c|c|c|}
\hline Machined material & $\begin{array}{c}\text { Cutting speed } \mathrm{v}_{\mathrm{c}} \\
{\left[\mathrm{m} \cdot \mathrm{min}^{-1}\right]}\end{array}$ & $\begin{array}{l}\text { Feed per tooth } \mathrm{f}_{\mathrm{z}} \\
{[\mathrm{mm}]}\end{array}$ & $\begin{array}{c}\text { Revolutions } \\
\mathrm{n}\left[\mathrm{min}^{-1}\right]\end{array}$ & $\begin{array}{c}\text { Feed speed } \\
\mathrm{V}_{\mathrm{f}}\left[\mathrm{m} \cdot \mathrm{min}^{-1}\right]\end{array}$ \\
\hline \multirow{12}{*}{ Titanium alloy UNS R56260 } & \multirow{3}{*}{50} & 0.25 & \multirow{3}{*}{343} & 0.086 \\
\hline & & 0.4 & & 0.137 \\
\hline & & 0.6 & & 0.206 \\
\hline & \multirow{3}{*}{80} & 0.25 & \multirow{3}{*}{549} & 0.137 \\
\hline & & 0.4 & & 0.22 \\
\hline & & 0.6 & & 0.329 \\
\hline & \multirow{3}{*}{100} & 0.25 & \multirow{3}{*}{686} & 0.172 \\
\hline & & 0.4 & & 0.274 \\
\hline & & 0.6 & & 0.412 \\
\hline & \multirow{3}{*}{130} & 0.25 & \multirow{3}{*}{893} & 0.223 \\
\hline & & 0.4 & & 0.357 \\
\hline & & 0.6 & & 0.536 \\
\hline
\end{tabular}


Figure 6 demonstrates that the smallest measured values of the cutting forces are, for constant feed per tooth milling $f_{z}=0.25 \mathrm{~mm}$, at a cutting speed $v_{c}=50 \mathrm{~m} \cdot \mathrm{min}^{-1}$ and feed rate $v_{f}=0.086 \mathrm{~m} \cdot \mathrm{min}^{-1}$. The chart also shows that the cutting components of forces $F_{x}, F_{y}$ and $F_{z}$ increase along with cutting speed $v_{c}$.

Figure 7 shows that the smallest measured values of the cutting forces are, for constant feed per tooth milling $f_{z}=0.4 \mathrm{~mm}$, at a cutting speed $v_{c}=80 \mathrm{~m} \cdot \mathrm{min}^{-1}$ and feed rate $v_{f}=0.219 \mathrm{~m} \cdot \mathrm{min}^{-1}$. For this feed per tooth, it is interesting that the cutting force values $F_{y}$ are identical for almost all cutting speeds $v_{c}$.

Figure 8 indicates that the smallest measured values of the cutting forces are, for constant feed per tooth conventional milling $f_{z}=$
$0.6 \mathrm{~mm}$, at a cutting speed $v_{c}=80 \mathrm{~m} \cdot \mathrm{min}^{-1}$ and feed speed $v_{f}=0.329 \mathrm{~m} \cdot \mathrm{min}^{-1}$. With this suggested feed per tooth $f_{z}$, it is clearly shown that the cutting speed $v_{c}$ should be somewhere in the range of $v_{c}=80-100 \mathrm{~m} \cdot \mathrm{min}^{-1}$, since failure to observe this interval results in high wear of the insert, followed by early fracture. Therefore, the cutting forces were not found at cutting speeds $v_{c}=50$ and $130 \mathrm{~m} \cdot \mathrm{min}^{-1}$ because the insert failed to withstand a single pass in the material.

\section{CONCLUSION}

For the evaluation of cutting forces, the cutting components of force $F_{x}$ (normal cutting

Dependence of cutting force components on cutting speed and feed per tooth $\mathrm{f}_{\mathrm{z}}=0.25 \mathrm{~mm}$

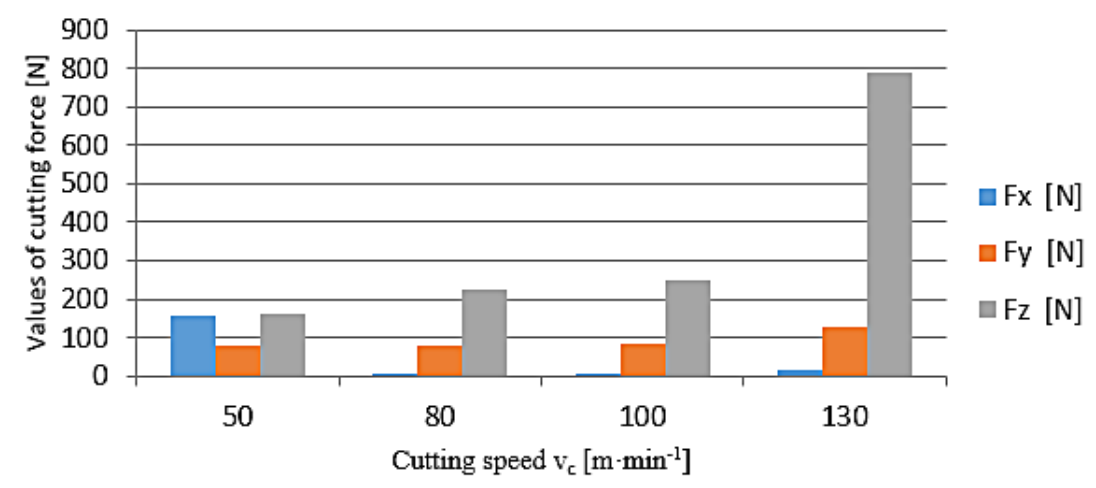

Fig. 3. Measured values of cutting force components during climb milling for continuous feed per tooth $\mathrm{f}_{\mathrm{z}}=0.25 \mathrm{~mm}$, cutting depth $\mathrm{a}_{\mathrm{p}}=0.5 \mathrm{~mm}$ and different cutting speeds $\mathrm{v}_{\mathrm{c}}$

Dependence of cutting force components on cutting speed and feed per tooth $\mathrm{f}_{\mathrm{z}}=0.4 \mathrm{~mm}$

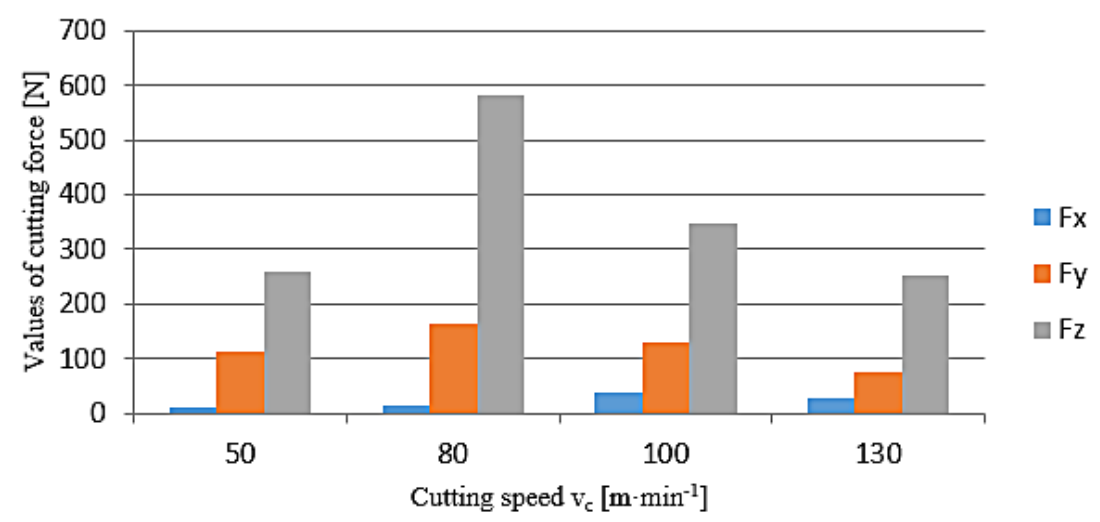

Fig. 4. Measured values of cutting force components during climb milling for continuous feed per tooth $\mathrm{f}_{\mathrm{z}}=0.4 \mathrm{~mm}$, cutting depth $\mathrm{a}_{\mathrm{p}}=0.5 \mathrm{~mm}$ and different cutting speeds $\mathrm{v}_{\mathrm{c}}$ 
Dependence of cutting force components on cutting speed and feed per tooth $\mathrm{f}_{\mathrm{z}}=0.6 \mathrm{~mm}$

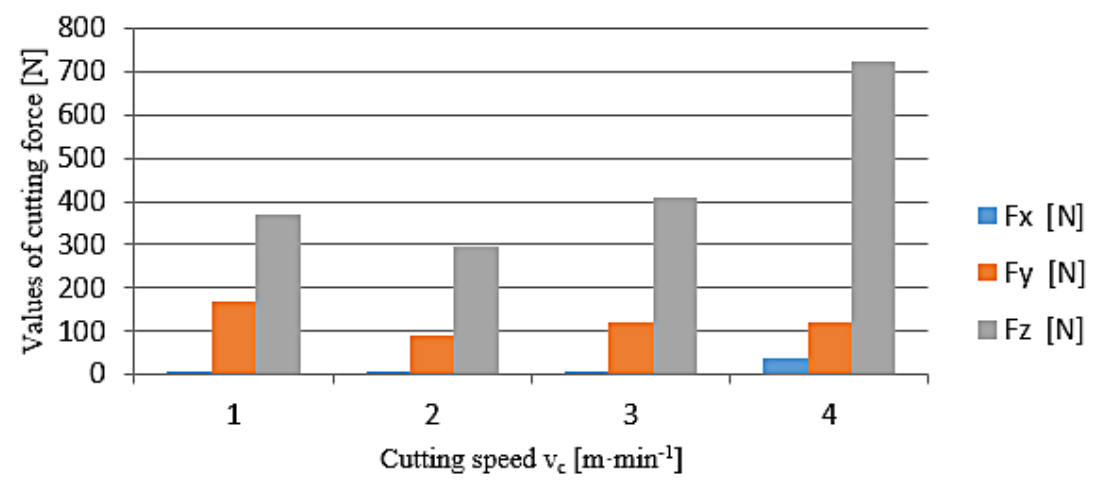

Fig. 5. Measured values of cutting force components during climb milling for continuous feed per tooth $\mathrm{f}_{\mathrm{z}}=0.6 \mathrm{~mm}$, cutting depth $\mathrm{a}_{\mathrm{p}}=0.5 \mathrm{~mm}$ and different cutting speeds $\mathrm{v}_{\mathrm{c}}$

\section{Dependence of cutting force components on cutting speed and feed per tooth $\mathrm{f}_{\mathrm{z}}=0.25 \mathrm{~mm}$}

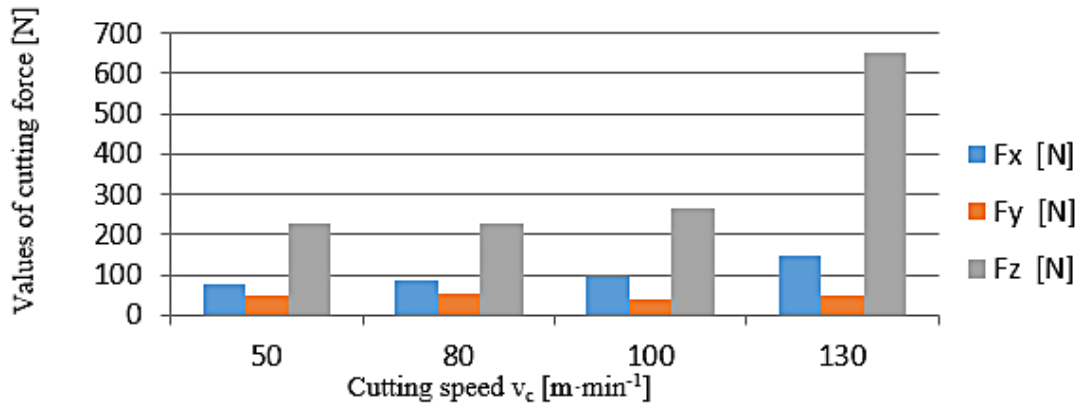

Fig. 6. Measured values of cutting force components during conventional milling for continuous feed per tooth $\mathrm{f}_{\mathrm{z}}=0.25 \mathrm{~mm}$, cutting depth $\mathrm{a}_{\mathrm{p}}=0.5 \mathrm{~mm}$ and different cutting speeds $\mathrm{v}_{\mathrm{c}}$

\section{Dependence of cutting force components on cutting speed and} feed per tooth $\mathrm{f}_{\mathrm{z}}=0.4 \mathrm{~mm}$

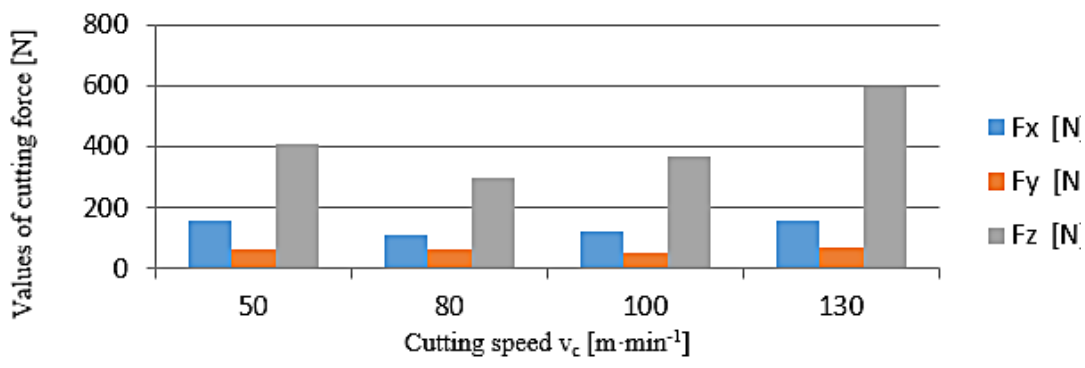

Fig. 7. Measured values of cutting force components during conventional milling for continuous feed per tooth $\mathrm{f}_{\mathrm{z}}=0.4 \mathrm{~mm}$, cutting depth $\mathrm{a}_{\mathrm{p}}=0.5 \mathrm{~mm}$ and different cutting speeds $\mathrm{v}_{\mathrm{c}}$

forces perpendicular to the tool feed direction), $F_{y}$ (cutting forces in the tool feed direction) and $F_{z}$ (compressive or passive cutting forces acting in the tool axis direction) were measured. On the basis of the results of the experiment, it is clear at what cutting parameters it is best to mill the UNS R56260 titanium alloy. It was also appropriate to find out which of the face milling methods (climb milling, conventional milling) is less prone to the cutting force magnitude.

In the case of climb milling, the lowest cutting forces were achieved with parameters: cutting speed $v_{c}=80 \mathrm{~m} \cdot \mathrm{min}^{-1}$, feed per tooth $f_{z}=0.25 \mathrm{~mm}$ and tool feed rate $v_{f}=0.137 \mathrm{~m} \cdot \mathrm{min}^{-1}$. The achieved values of cutting forces are: $F_{x}=5 \mathrm{~N}, F_{y}=77 \mathrm{~N}$ and $F_{z}=226 \mathrm{~N}$. 
Dependence of cutting force components on cutting speed and feed per tooth $\mathrm{f}_{\mathrm{z}}=0.6 \mathrm{~mm}$

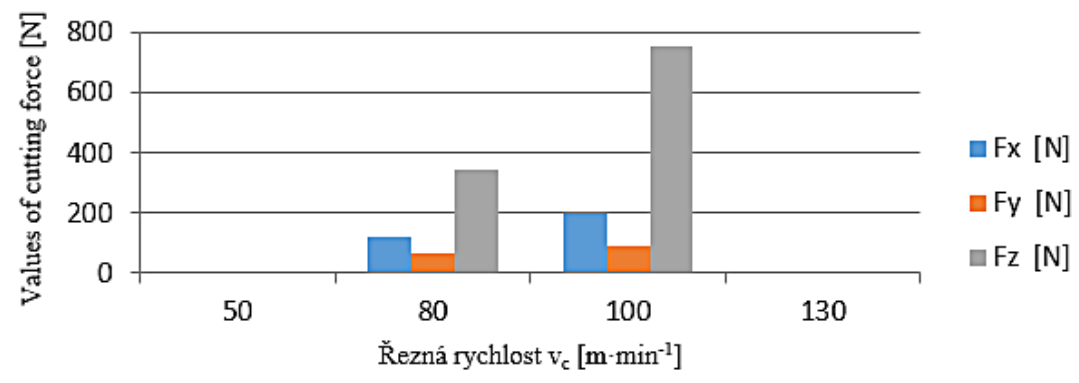

Fig. 8. Measured values of cutting force components during conventional milling for continuous feed per tooth $\mathrm{f}_{\mathrm{z}}=0.6 \mathrm{~mm}$, cutting depth $\mathrm{a}_{\mathrm{p}}=0.5 \mathrm{~mm}$ and different cutting speeds $\mathrm{v}_{\mathrm{c}}$

In the case of conventional milling, the lowest cutting forces were achieved with milling parameters: cutting speed $v_{c}=50 \mathrm{~m} \cdot \mathrm{min}^{-1}$, feed per tooth $f_{z}=0.25 \mathrm{~mm}$ and tool feed speed $v_{f}=0.085 \mathrm{~m} \cdot \mathrm{min}^{-1}$. The achieved values of cutting forces are $F_{x}=79 \mathrm{~N}, F_{y}=48 \mathrm{~N}$ and $F_{z}=230 \mathrm{~N}$.

According to the measured values of cutting forces and their subsequent conversion into charts, it can be deduced that feed per tooth $f_{z}$ has the greatest influence on increasing the cutting forces. In the case of the resulting smallest cutting forces, there is no such a significant difference between climb milling and conventional milling. In the case of climb milling, the cutting component $F_{x}$ is much smaller than in conventional milling. In the case of other cutting components of forces $F_{y}$ and $F_{z}$, the resulting values do not differ so much in most cases, which indicates that it does not matter so much on the milling method but rather on the production strategy and operation.

Nowadays, the machining of titanium alloys is of great importance, mainly due to the ever-expanding field of application of these alloys, especially in the aerospace industry. As it has been written in many articles dealing with milling technology of titanium alloys, the cutting conditions play an important role in milling. They influence both the wear and durability of the tool, as well as the distribution of the individual components of the cutting forces, or whether some of the cooling technologies of the cutting point have been used. The right choice of cutting conditions can increase the machining efficiency, tool life, but also the quality of the resulting surface of the machined part.

\section{REFERENCES}

1. Görög A., D. Stančeková, M. Kapustová, I. Görögová, I. Miturska, Influence of Selected Cutting Conditions on Cutting Forces. Advances in Science and Technology-Research Journal, (2017)

2. Sliva A., R. Brazda, A. Prochazka, G. S. Martynkova, K. C. Barabaszova, Investigation of geometric properties of modified titanium white by fluidisation for use in the process of transport, handling, processing and storage. Journal of nanoscience and nanotechnology. 2997 - 3001 (2019)

3. Barnett-Ritcey, D., Elbastawi, M.A., Tool performance in high speed finish milling of Ti6Al4V. American Society of Mechanical Engineers, Manufacturing Engineering Division, MED, 211 - 219 (2002)

4. Guilin, L., Research on tool wearing on milling of TC21 titanium alloy. IOP Conference Series: Earth and Environmental Science, (2017)

5. Kratochvíl J., M. Sadílek, J. Mrazik, The effect of chip former on power loading of recessing tool. Advances in Science and Technology-Research Journal, (2017)

6. Ji, W., Liu, X., Wang, L., Sun, S., Experimental evaluation of polycrystalline diamond (PCD) tool geometries at high feed rate in milling of titanium alloy TC11. International Journal of Advanced Manufacturing Technology, 1549 - 1555 (2015)

7. Kopierfräser [online]. In: . IngersollGmbh, 2017 [cit. 2017-03-05]. Available: http://www.imccompanies.com/Ingersollcatalog/Item.aspx?cat $=30633$ $22 \&$ fnum $=174 \&$ mapp $=$ ML \&GFSTYP $=$ M.

8. Li, A., Zhao, J., Hou, G, Effect of cutting speed on chip formation and wear mechanisms of coated carbide tools when ultra-high-speed face milling titanium alloy Ti-6Al-4V. Advances in Mechanical Engineering, (2017)

9. Liu, J. J., Chen, C., Yang, Y. F., Li, L., Zhao, W., Experimental research of milling force and cutting temperature of TB2 titanium alloy in liquid nitrogen 
cooling. Materials Science Forum, 36 - 42 (2016)

10. Member IMC group [online]. In: . Ingersoll 2017 [cit. 2017-03-05]. Available: http://ecat.ingersollimc.com/ecat/ProductDetails.aspx?ID=17895.

11. Microtes [online]. In: Mitutoyo, 2017 [cit. 2017-03-05]. Available: http://www.microtes.cz/ Mitutoyo/drsnomery-SJ210aSJ301-M.pdf.

12. Okada, M., Hosokawa, A., Askawa, N., Ueda, T., End milling of stainless steel and titanium alloy in an oil mist environment. International Journal of Advanced Manufacturing Technology, 1255-1266 (2014)

13. Safari, H., Sharif, S., Izman, S., Jafari, H., Surface integrity characterization in high-speed dry end milling of Ti-6Al-4V titanium alloy. International Journal of Advanced Manufacturing Technology, $651-657$ (2015)

14. Sun, H., Xiao, H., Li, L., Experimental study on cutting force and cutting power in high feed milling of Ti5Al5Mo5VCrFe. Materials Science Forum, $88-93(2015)$

15. Schindlerová V., I. Šajdlerová, Influence of Tool Wear on Material Flow. Advances in Science and Technology-Research Journal, (2017)

16. Xu, J., Rong, B., Zhang, H.Z., Wang, D.S., Li, L., Investigation of cutting force in high feed milling of Ti6Al4V. Materials Science Forum, 106 - 109 (2013) 